\title{
Leucemia/Linfoma de células T del adulto y criptococosis sistémica: Reporte de dos casos en un hospital peruano
}

Milagros Altamirano-Molina* 1,a , Giancarlo Pérez-Lazo ${ }^{1, b}$, Ana Alvarez Barcena 1,c, Víctor Delgado Gonzáles ${ }^{1, d}$, Renee Eyzaguirre Zapata ${ }^{1, a}$

\section{RESUMEN}

La leucemia/linfoma de células T adulto (LLCTA) es una neoplasia linfoide causada por el virus linfotrópico humano de células T tipo 1 (HTLV-1), retrovirus endémico en nuestro país. Tiene una presentación heterogénea, con variedades de pobre pronóstico e infecciones oportunistas que lo ensombrecen aún más. Se presentan dos casos de pacientes con variedades agresivas de la enfermedad (aguda y linfomatosa) complicadas con criptococosis sistémica. Reforzamos la necesidad de un enfoque diagnóstico completo y un monitoreo continuo de agentes oportunistas en el paciente con LLCTA adaptado a nuestro contexto epidemiológico.

Palabras clave: Leucemia-Linfoma de células T del adulto; Infecciones oportunistas; Criptococosis (Fuente: DeCS BIREME).

\section{Adult T-cell leukemia/lymphoma and systemic cryptococcosis: report of two cases in a Peruvian hospital}

\section{ABSTRACT}

Adult T-cell leukemia/lymphoma (ATLL) is a lymphoid neoplasm caused by the human T-cell lymphotropic virus type 1 (HTLV-1), an endemic retrovirus in our country.

It has a heterogeneous presentation, with sub types of poor prognosis, and opportunistic infections that worsen the prognosis. We present two cases with aggressive varieties of the disease (acute and lymphomatous) complicated by systemic cryptococcosis. It is necessary to conduct a complete diagnostic approach and continuous monitoring of opportunistic agents in patients with ATL adapted to our epidemiological context.

Keywords: Leukemia-lymphoma, Adult T-cell; Opportunistic infections; Cryptococcosis (Source: MeSH NLM).

1. Hospital Guillermo Almenara Irigoyen. EsSalud. Lima, Perú.

a. Médico, Asistente. Servicio de Hematología.

b. Médico, Asistente. Servicio de Infectología.

c. Médico, Residente. Servicio de Hematología.

d. Médico, Asistente. Servicio de Anatomía patológica.

${ }^{*}$ Autor corresponsal. 


\section{INTRODUCCIÓN}

La leucemia/linfoma de células T adulto (LLCTA) es una neoplasia de células $T$ periféricas en la que se produce proliferación de linfocitos $\mathrm{T}$ infectados por virus linfotrópico humano de células T tipo 1 (HTLV-1). Este retrovirus no está tan extendido a nivel mundial en comparación con el virus de la inmunodeficiencia humana (VIH), ya que tiene cierta distribución epidemiológica, es endémico en países de Sudamérica, suroeste de Japón, islas del Caribe y África central ${ }^{(1,2)}$. En Japón se reporta que aproximadamente 1,1 millón de personas están infectadas, y cerca de 1000 presentan LLCTA al año ${ }^{(3)}$.

Ocurre principalmente en población adulta, mayor de 50 años y es ligeramente más frecuente en los varones. La principal vía de transmisión del virus es a través de la lactancia, y las menos probables, las vías sexual o parenteral (4). La presentación clínica es heterogénea, Shimoyama en 1991, describió 4 subtipos: aguda, linfomatosa, crónica y latente. Las dos primeras constituyen las variantes de tipo agresivo y pobre pronóstico, con un tiempo de sobrevida de 6 a 10 meses ${ }^{(5)}$.

El tratamiento en estas variantes incluye quimioterapia y uso de antiretrovirales, como interferón alfa y zidovudina, respectivamente, y se busca consolidar la respuesta con un trasplante alogénico ${ }^{(6,7)}$. Sin embargo, muy pocos pacientes tienen esta opción, ya sea por la edad de presentación, la falta de respuesta al tratamiento y la alta tasa de complicaciones infecciosas, que empobrecen aún más el pronóstico. Entre estas últimas, tenemos las producidas por gérmenes oportunistas, que se presentan tanto en portadores como en sintomáticos ${ }^{(8)}$.

A continuación, se describen dos casos de variantes agresivas de LLCTA asociados a criptococosis sistémica, diagnosticados y manejados en el hospital Guillermo Almenara Irigoyen en Lima, Perú que evolucionaron desfavorablemente.

\section{CASO CLÍNICO}

\section{CASO 1}

Paciente mujer de 28 años, natural y procedente de Lima. Inició enfermedad con la aparición progresiva de adenopatías cervicales, axilares e inguinales asociada a sudoración profusa y pérdida de peso de $6 \mathrm{~kg}$ durante los últimos 3 meses, por lo que acudió a emergencia. Al ingreso se identificaron adenopatías múltiples y hepatoesplenomegalia. El hemograma evidenció hemoglobina $12 \mathrm{~g} / \mathrm{dL}$, leucocitos $5000 \mathrm{cel} / \mathrm{mm}^{3}$ sin linfocitosis, y plaquetas $350000 \mathrm{cel} / \mathrm{mm}^{3}$. Otros exámenes de laboratorio revelaron calcio sérico $8,9 \mathrm{mg} / \mathrm{dL}$, lactato deshidrogenasa (LDH) $1213 \mathrm{UI} / \mathrm{L}$ y $\beta-2$ microglobulina $2196 \mathrm{mg} / \mathrm{L}$. El test de quimioluminiscencia para HTLV1 fue reactivo.

Se realizó biopsia de ganglio cervical, con reporte histológico de linfoma T periférico variante no especificado (clasificación OMS 2017), y expresión difusa de CD45, CD3 y CD5; CD20 focal (Figura 1). Se descartó infiltración medular por biopsia de hueso, y se concluye en LLCTA variante linfomatosa estadio clínico III-B, IPI-2 (índice pronóstico internacional), de riesgo intermedio bajo.
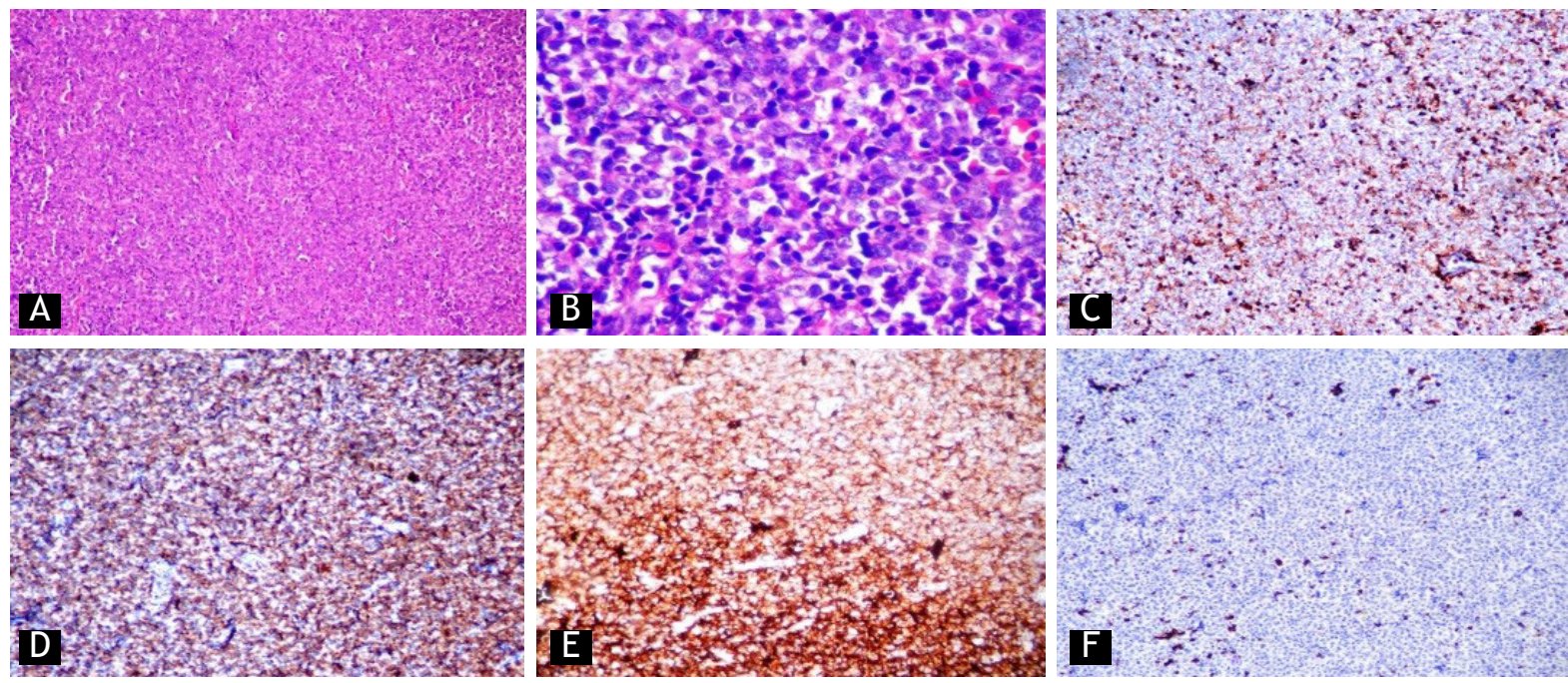

Figura 1. Biopsia de ganglio cervical. A) Proliferación difusa de células linfoides de tamaño pequeño a intermedio que borra totalmente la estructura ganglionar normal (10x, H-E). B) Células con núcleos irregulares, algunos con nucléolo prominente, picnosis nuclear y mitosis (40x, H-E). C-D- E- F) El estudio inmunohistoquímico muestra positividad para CD45, CD3 y CD5, y CD20 negativo, respectivamente (10x) 
Una vez confirmado el diagnóstico, se solicitó recuento de T CD4+ cuyo resultado fue $499 \mathrm{cel} / \mathrm{mm}^{3}$. El screening para Strongyloides stercoralis en heces fue negativo y la carga viral de citomegalovirus indetectable.

La paciente recibió un ciclo de quimioterapia $\mathrm{EPOCH}$ (etopósido, prednisona, vincristina, ciclofosfamida y doxorrubicina) y, una vez concluida, zidovudina $600 \mathrm{mg}$ al día y una sola dosis de interferón alfa de 9 millones $\mathrm{UI} / \mathrm{m}^{2} /$ día SC; así como profilaxis con cotrimoxazol y fluconazol. En el día +10 posquimioterapia cursó con neutropenia febril por foco urinario (Klebsiella pneumoniae productora de betalactamasa), recibió cobertura antibiótica y factor estimulante de colonias de granulocitos. La evolución clínica fue favorable con recuperación hematológica; sin embargo, en el día
+20 posquimioterapia cursa nuevamente febril, y se evidencia en los hemocultivos periféricos el crecimiento de levaduras de Cryptococcus neoformans, por lo que se inició cobertura antifúngica con anfotericina $B$ deoxicolato $0,7 \mathrm{mg} / \mathrm{kg} /$ día más fluconazol $300 \mathrm{mg} /$ día durante la fase de inducción por 16 días, seguida de consolidación con fluconazol $300 \mathrm{mg} /$ día. El antígeno sérico para Cryptococcus cualitativo fue positivo, sin compromiso del sistema nervioso central y con documentación microbiológica de negativización de cultivos. Sin embargo, en el día +35 posquimioterapia se agregó insuficiencia respiratoria aguda. En la tomografía de tórax se evidenciaron nódulos pulmonares bilaterales (Figura 2) sugerentes de compromiso pulmonar fúngico con desenlace fatal.
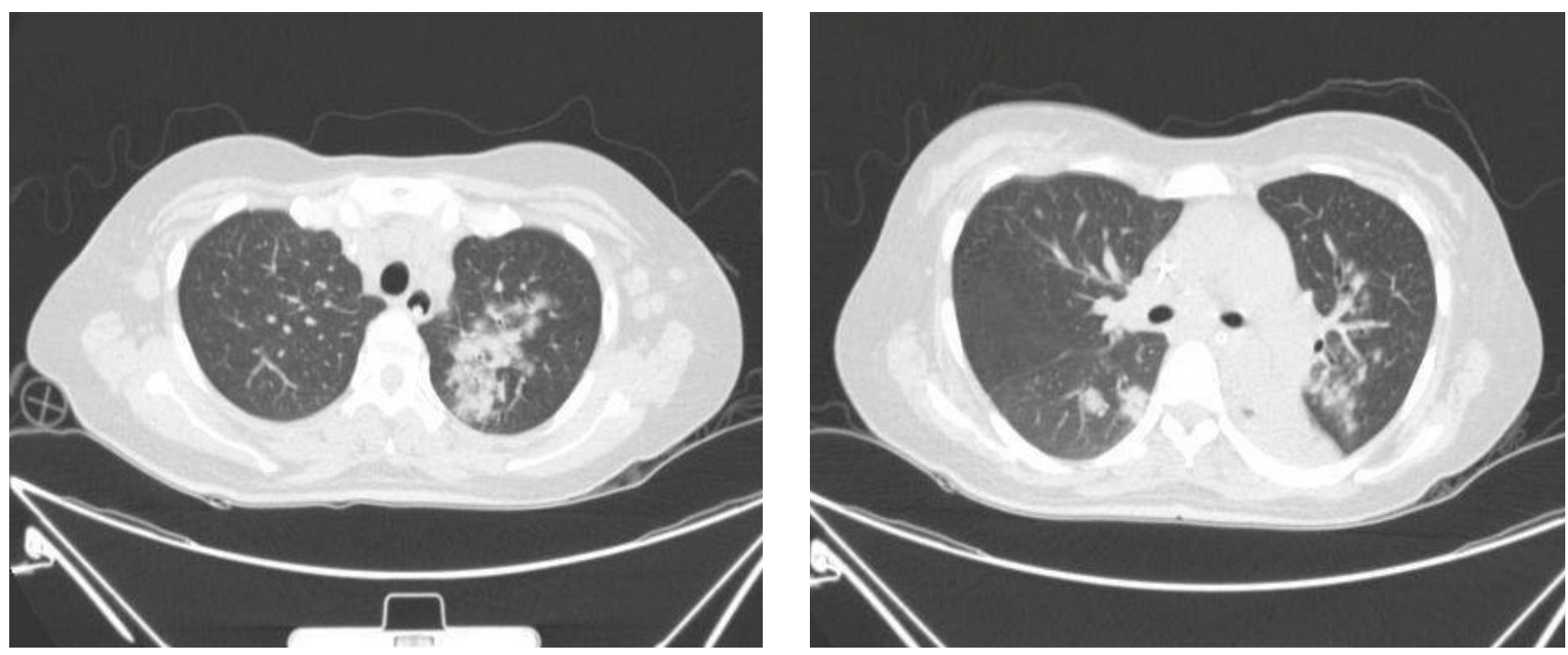

Figura 2. Tomografía espiral multicorte (TEM) de tórax. Se evidencian nódulos múltiples bilaterales en relación a probable infección fúngica

\section{CASO 2}

Paciente mujer de 68 años, natural y procedente de Lima, con antecedente de hipertensión arterial, que refirió cursar con dolor costal derecho, hiporexia y pérdida de peso de aproximadamente $3 \mathrm{~kg}$ en el último mes, motivo de ingreso a emergencia. El examen físico inicial no fue sugerente. El hemograma periférico evidenció leucocitosis $\left(12040 \mathrm{cel} / \mathrm{mm}^{3}\right.$ ) con predominio de linfocitos en $70 \%$, DHL $314 \mathrm{mg} / \mathrm{dL}$, calcio sérico normal y B-2 microglobulina en $3165 \mathrm{mg} / \mathrm{L}$. En la tomografía de tórax se identificó nódulo pulmonar basal derecho (Figura 3a), por lo que es referida a neumología para estudio.

Se realizó broncofibroscopía, y en el lavado broncoalveolar se obtuvieron levaduras de Cryptococcus neoformans, hallazgo corroborado luego con estudio histológico (Figura 3b). El antígeno sérico cualitativo resultó positivo, por lo que se inició tratamiento con anfotericina $\mathrm{B}$ deoxicolato $0,7 \mathrm{mg} / \mathrm{kg} /$ día y fluconazol $400 \mathrm{mg} /$ día durante 21 días en la fase de inducción, con posterior consolidación con fluconazol a la misma dosis. 

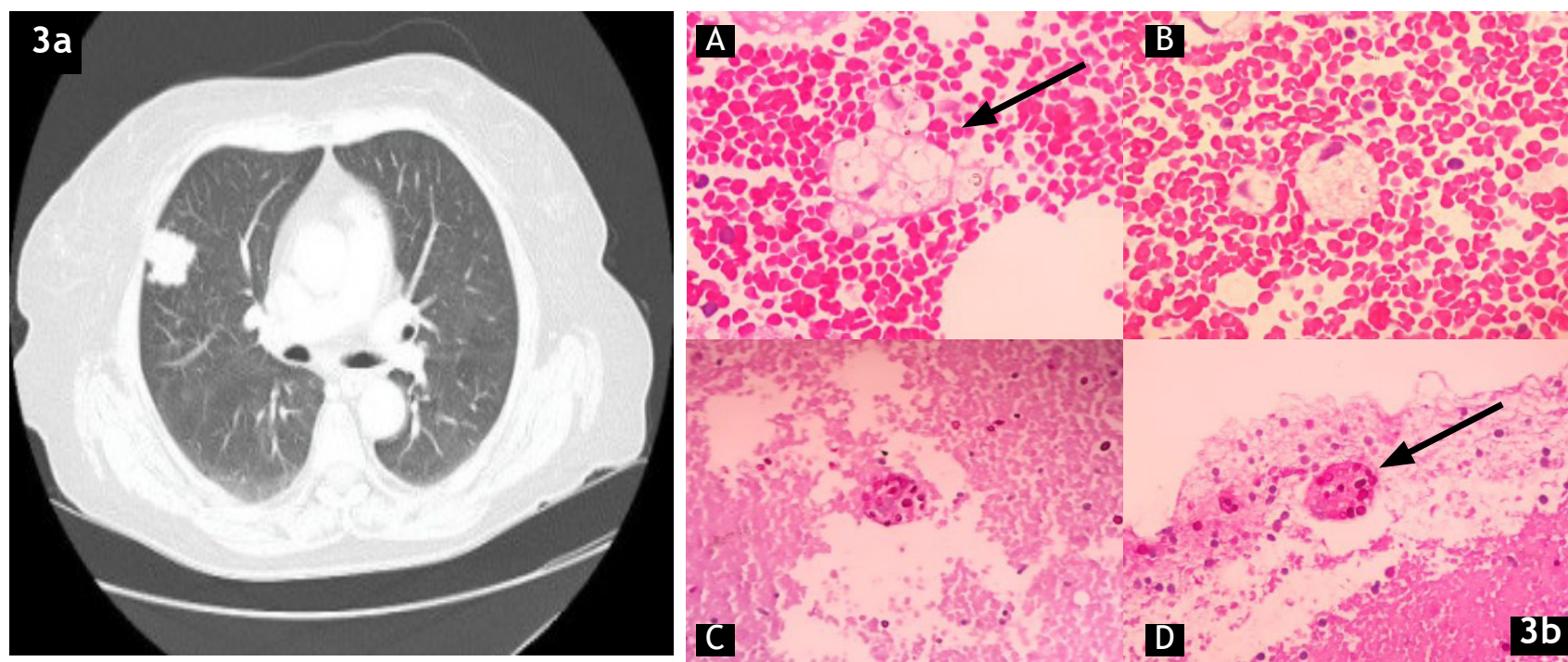

Figura 3a. Tomografía espiral multicorte (TEM) tórax. Tumoración sólida de 2,8 8 2,9 cm, de bordes irregulares a nivel del segmento III de hemitórax derecho 3b. Coágulo sanguíneo con presencia de macrófagos conteniendo levaduras de Cryptococcus. A-B) HE 40X. C-D) PAS 40X

El test de quimioluminiscencia y Western Blot fueron positivos para HTLV1, el recuento de linfocitos T CD4+ fue $5920 \mathrm{cel} / \mathrm{mm} 3$. Se evaluó la lámina periférica, y se evidenció la presencia de linfocitos atrebolados (Figura 4a).
El estudio de médula ósea concluye mediante citometría de flujo en proceso linfoproliferativo de células T maduras con expresión de CD45, CD3, CD4, CD5, negativo para CD7 (Figura 4b).
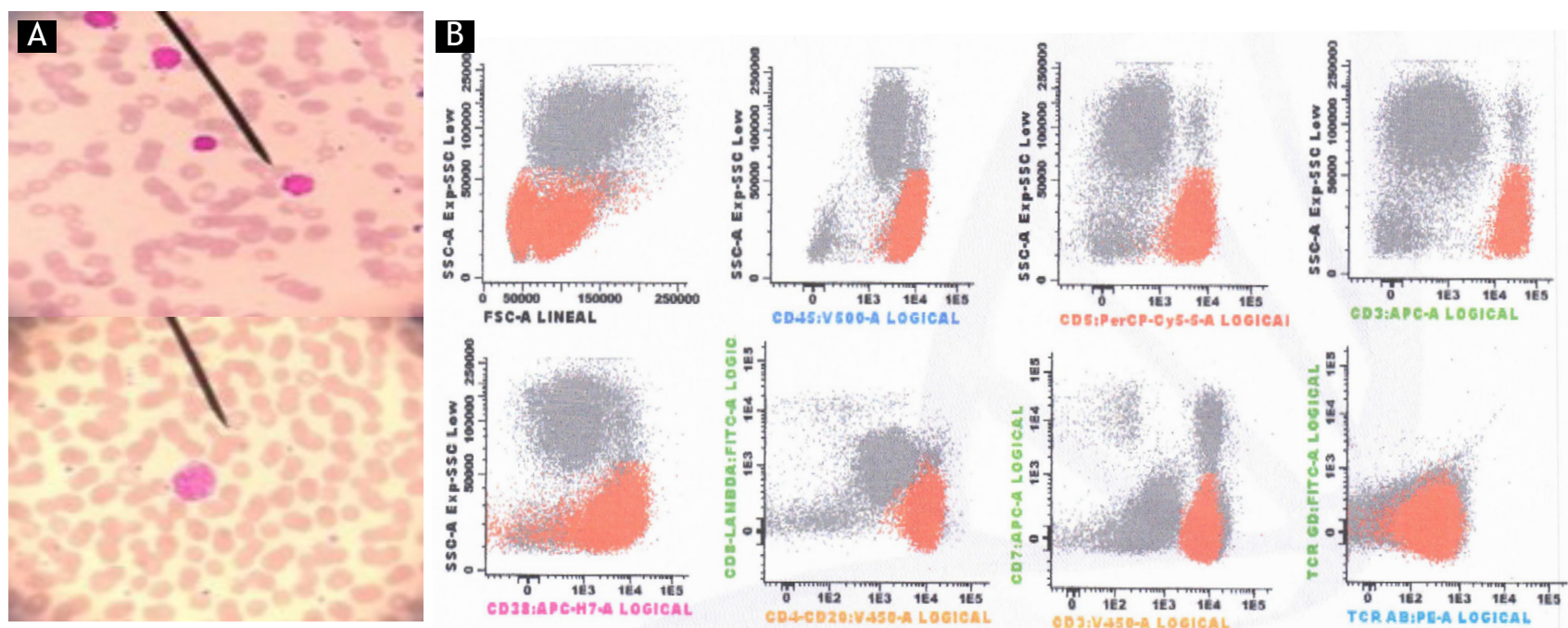

Figura 4. A) Linfocitos de tamaño medio, con núcleo irregular o convoluto (flower cells). B) Se identifica población pequeña sin complejidad granular en 69,96\%, que expresa CD45++, CD3++, CD4++, CD5++, TCRab+. Negativa a CD7, CD10, TCRgd

La evolución fue tórpida, con desarrollo de meningitis e insuficiencia respiratoria aguda, con tomografía de tórax sugestiva de neumonía por Pneumocystis jirovecii y desenlace fatal a pesar de cobertura antimicrobiana y antifúngica. 


\section{DISCUSIÓN}

La infección por Cryptococcus spp. representa una patología oportunista rara asociada a desórdenes linfoproliferativos. La incidencia estimada en pacientes con neoplasias hematológicas oscila entre $0,6 \%-2,4 \%$, y es mayor en pacientes con leucemia linfocítica crónica (LLC) y linfoma de Hodgkin ${ }^{(9)}$; sin embargo, solo hay reportes de casos en asociación con LLCTA. Maeda et al. en una cohorte retrospectiva japonesa reportan una prevalencia de $0,5 \%$ (17 casos) en pacientes adultos con LLCTA ${ }^{(10)}$. A pesar de que es una complicación infrecuente en este contexto se ha sugerido la potencial asociación entre criptococosis y el estado de portador de HTLV-1 ${ }^{(11,12)}$.

Las infecciones oportunistas han sido descritas en pacientes con diversas variantes de LLCTA, algunos reportes detallan infecciones en estados no agudos de la enfermedad. Tashiro et al. reconocieron el desarrollo de infecciones oportunistas en pacientes portadores de HTLV-1 y en pacientes con variante latente, que progresaron rápidamente a formas agudas. Los casos reportados incluyeron neumonía por Cryptococcus neoformans (1 de ellos coinfectado con Pneumocystis jirovecii) cuya presentación precedió en 14 a 16 meses a la forma aguda de LLCTA ${ }^{(13)}$. Rhew et al. describieron un caso de LLCTA variante crónica que presentó neumonía por Pneumocystis jirovecii, Cryptococcus neoformans, Mycoplasma pneumoniae, y Mycobacterium avium complex ${ }^{(14)}$. Takasaki también describe en estas formas indolentes (latente y crónica) 2 casos de meningitis por Cryptococcus neoformans, complicaciones que se presentaron al momento del diagnóstico ${ }^{(15)}$. El estudio reciente de Malpica et al. en áreas de prevalencia de Estados Unidos reportó 1 caso de criptococosis en la variante aguda de LLCTA (16), y en la revisión de la literatura en Pubmed, Google Académico y SciELO, no encontramos casos en la variante linfomatosa de LLCTA. Reportamos los 2 primeros casos de criptococosis en pacientes con LLCTA en Perú.

El primer caso corresponde a un paciente joven (dato inusual en este diagnóstico) que presentó variante linfomatosa de la enfermedad, ya que no hubo evidencia de linfocitosis en la periferia, con fungemia y compromiso pulmonar posible por Cryptococcus neoformans en el contexto de recuperación hematológica luego de la quimioterapia. En el segundo caso, el diagnóstico inicial fue de criptococosis pulmonar, seguido de la confirmación de HTLV-1 y de proceso linfoproliferativo asociado con la demostración de células típicas en flor en la periferia, compatible con una variante aguda. En este último, el estado general y el compromiso meníngeo no permitieron iniciar algún tipo de tratamiento contra LLCTA. El compromiso respiratorio en el segundo caso se atribuyó a Pneumocystis jirovecii (no contamos con PCR para este agente en la institución), tal como aparece en las coinfecciones descritas en los reportes de Tashiro y Rhew. Adicionalmente, como parte de la manifestación sistémica de criptococosis se han reportado también el compromiso ganglionar, cutáneo, oftalmológico y hepático en pacientes con LLCTA ${ }^{(17-19)}$. Los 2 casos tuvieron desenlace fatal por las intercurrencias infecciosas, similar a otras publicaciones ${ }^{(11,12,14)}$.

El predominio de células T CD4+ infectadas en HTLV-1 es un fenómeno reconocido en portadores, puesto que se afectan preferentemente las células $T$ reguladoras $C D 4+C D 25+$, que son el mayor reservorio de provirus de HTLV-1. Esto promueve la inflamación y juega un rol en la transformación y desarrollo de LLCTA. Las células reguladoras se incrementan en condiciones de infecciones oportunistas (por ejemplo, hiperinfestación por Strongyloides), es por ello que algunos autores proponen el monitoreo de células $T$ reguladoras $C D 4+C D 25+$ como marcador pronóstico en pacientes portadores y en aquellos con variantes latentes de LLCTA ${ }^{(20)}$. En nuestros pacientes los recuentos de células T CD4+ al momento del diagnóstico de LLCTA estuvieron por encima de $400 \mathrm{cel} / \mathrm{mm}^{3}$; sin embargo, no se emplearon otros marcadores, como el CD25+, porque no disponemos del reactivo en el hospital, para discernir entre células infectadas versus linfocitos funcionales.

El tratamiento para infecciones por Cryptococcus neoformans en el contexto local, donde no contamos con 5-flucitosina, nos lleva a usar los esquemas de anfotericina deoxicolato más fluconazol, el cual se correlaciona con un clearance fúngico temprano en pacientes $\mathrm{VIH}{ }^{(21)}$. La mayoría de las recomendaciones para el manejo de este agente oportunista en inmunocomprometidos no VIH son extrapolados de estudios en pacientes con infección por $\mathrm{VIH}$. Ambos casos presentaron enfermedad diseminada, y algunos autores recomiendan el uso de formas liposomales de anfotericina por 4-6 semanas (terapia de inducción) más flucitosina; seguidas de fluconazol $400-800 \mathrm{mg}$ diarios por 8 semanas (terapia de consolidación) y finalmente, fluconazol 200-400 mg diarios por 6-12 meses (terapia de mantenimiento). Adicionalmente, la corrección o reducción de la inmunosupresión (gradual) es punto clave en la terapéutica (22). Acorde a estas recomendaciones consideramos que la duración de la terapia de inducción fue subóptima, así como las dosis de fluconazol en fase de consolidación, lo cual acarreó el compromiso sistémico y desenlace fatal en ambas situaciones; además de no disponer oportunamente de la forma liposomal de anfotericina. También se ha reportado en una revisión sistemática reciente, la resistencia de base a fluconazol en $12 \%$, lo cual es una importante consideración para las recaídas de meningitis o respuestas subóptimas a la terapia. Aún no hay puntos de corte establecidos para definir resistencia a fluconazol, lo cual representó una de las limitaciones de este estudio ${ }^{(23)}$. 
La evidencia del rastreo del antígeno criptocócico en pacientes inmunocomprometidos no $\mathrm{VIH}$ es escasa. Sin embargo, la antigenemia para Cryptococcus en individuos con HTLV-1 (tanto en asintomáticos con recuentos de células T normales y en aquellos con LLCTA) puede ser útil en contextos endémicos como el nuestro, a pesar de que no hay guías establecidas que lo indiquen ${ }^{(11,24)}$.

En conclusión, es importante la identificación temprana de agentes oportunistas que pueden condicionar progresión a formas agudas en pacientes con LLCTA; y, en contextos endémicos como el nuestro, considerar a Cryptococcus spp. como un agente que puede presentarse en cualquier variante de LLCTA. Es importante evaluar la duración del tratamiento en inmunosuprimidos no VIH con manifestaciones sistémicas de criptococosis, así como la utilidad y efectividad de la terapia de combinación con anfotericina deoxicolato más fluconazol; pues las formas liposomales de anfotericina están incluidas en el petitorio de nuestra institución como terapia de segunda línea.

\section{REFERENCIAS BIBLIOGRÁFICAS}

1. Proietti FA, Carneiro-Proietti AB, Catalan-Soares BC, Murphy EL. Global epidemiology of HTLV-I infection and associated diseases. Oncogene. 2005; 24(39): 6058-68.

2. Utsunomiya A, Choi I, Chihara D, Seto M. Recent advances in the treatment of adult T-cell leukemia-lymphomas. Cancer Sci. 2015; 106: 344-351.

3. Chihara D, Ito H, Matsuda T, Katanoda K, Shibata A, Taniguchi S et al. Association between decreasing trend in the mortality of adult T-cell leukemia / lymphoma and allogeneic hematopoietic stem cell transplants in Japan: analysis of Japanese vital statistics and Japan Society for Hematopoietic Cell Transplantation (JSHCT). Blood Cancer J. 2013; 3(11): e159.

4. Tsukasaki K, Tobinai K. Human T-cell lymphotropic virus type I-associated adult T-cell leukemia-lymphoma: new directions in clinical research. Clin Cancer Res. 2014;20(20):5217-25.

5. Shimoyama M. Diagnostic criteria and classification of clinical subtypes of adult T-cell leukaemia-lymphoma. A report from the Lymphoma Study Group (1984-87). Br J Haematol 1991; 79: 428-37.

6. Bazarbachi A, Suarez F, Fields P, Hermine O. How I treat adult T-cell leukemia/lymphoma. Blood. 2011; 118 (7): 1736-45.

7. Katsuya $H$, Ishitsuka K. Treatment advances and prognosis for patients with adult T-cell leukemia-lymphoma. J Clin Exp Hematop. 2017;57(3):87-97.

8. Maeda T, Babazono A, Nishi T, Yasui M, Matsuda S, Fushimi k, et al. The Impact of Opportunistic Infections on Clinical Outcome and Healthcare Resource Uses for Adult T Cell Leukaemia. Plos One. 2015; 10(8): 2-12.

9. Dioverti M, Parikh S, Osmon D, Habermann T, Tande A. Cryptococcus neoformans infections in patients with lymphoproliferative neoplasms. Leuk Lymphoma. 2018,6:1-7.

10. Maeda T, Babazono A, Nishi T, Yasui M, Matsuda S, Fushimi K, et al. The Impact of Opportunistic Infections on Clinical Outcome and Healthcare Resource Uses for Adult T Cell Leukaemia. PLOS ONE. 2015;10(8): e0135042.

11. Chalkias S, Doweiko J, Eliopoulos G. An enabling act. Open Forum Infect Dis. 2014; 1(1): ofu008.

12. Marsh BJ. Infectious complications of human T cell leukemia/ lymphoma virus type I infection. Clin Infect Dis. 1996;23(1):138-45.

13. Tashiro T, Yamasaki T, Nagai H, Kikuchi H, Nasu M. Immunological

studies on opportunistic infection and the development of adult T-cell leukemia. Intern Med 1992;31:1132-36.

14. Rhew DC, Gaultier CR, Daar ES, Zakowski PC, Said J. Infections in patients with chronic adult T-cell leukemia/lymphoma: Case report and review. Clin Infect Dis. 1995;21(4):1014-6.

15. Takasaki $Y$, Iwanaga M, Imaizumi $Y$, Tawara M, Joh T, Kohno T et al. Long-term study of indolent adult T-cell leukemia-lymphoma. Blood. 2010;115(22):4337-43.

16. Malpica L, Pimentel A, Reis I, Gotuzzo E, Lekakis L, Komanduri K. Epidemiology, clinical features, and outcome of HTLV-1-related ATLL in an area of prevalence in the United States. Blood Adv. 2018;2(6), 607-20.

17. Miyoshi I, Hatakeyama N, Daibata M, Taguchi H. Cutaneous and nodal cryptococcosis in an ATL Patient. Intern Med. 2006;45(19):1105-06.

18. Yamada W, Yamada H, Murata K, Kosugi H, Asano Y, Mochizuki $\mathrm{K}$, Ishida K. Case of cryptococcal choroiditis in adult with T-cell leukemia/lymphoma. J Infect Chemother. 2018; S1341321X(18)30190-9.

19. Suzuki T, Ichiki Y, Kamihira T, Akamine M, lida M, Ogawa K, Fujisawa K. A case of hepatic cryptococcosis complicated by adult T-cell leukemia. Nihon Shokakibyo Gakkai Zasshi. 112(12):2168-75.

20. Tanaka T, Sekioka T, Usui M, Imashuku S. Opportunistic Infections in Patients with HTLV-1 Infection. Case Rep Hematol. 2015:943867. .

21. Concha-Velasco F, González-Lagos E, Seas C, Bustamante B. Factors associated with early mycological clearance in HIV-associated cryptococcal meningitis. PLoS One. 2017;12(3): e0174459.

22. Henao-Martínez AF, Chastain DB, Franco-Paredes C. Treatment of cryptococcosis in non-HIV immunocompromised patients. Curr Opin Infect Dis. 2018;31(4):278-85.

23. Bongomin F, Oladele RO, Gago S, Moore CB, Richardson MD. A systematic review of fluconazole resistance in clinical isolates of Cryptococcus species. Mycoses. 2018;61(5):290-97.

24. NCCN Guidelines [Internet]. Clinical Practice Guideliness in Oncology.T cell-Lyphomas.Version.2019. [citado 1 de agosto de 2018]. Disponible en: https://www.nccn.org/professionals/ physician_gls/pdf/t-cell.pdf

Fuentes de financiamiento:

Este artículo ha sido financiado por los autores.

Conflictos de interés:

Los autores declaran no tener ningún conflicto de interés.

Correspondencia:

Milagros A. Altamirano Molina

Dirección: Av. Grau Nro. 800. La Victoria- Lima, Perú.

Teléfono: 980589313 / 5649402

Correo electrónico: milagros.altamirano2@gmail.com

Recibido: 16 de octubre de 2018

Evaluado: 09 de noviembre de 2018 Aprobado: 04 de diciembre de 2018.

(c) La revista. Publicado por Universidad de San Martín de Porres, Perú. (cc) вr $_{\text {B }}$ Licencia de Creative Commons Artículo en acceso abierto bajo términos de Licencia Creative Commons Atribución 4.0 Internacional. (http://creativecommons.org/licenses/by/4.0/)

\section{ORCID iDs}

Milagros Altamirano-Molina Giancarlo Pérez-Lazo Renee Eyzaguirre Zapata Víctor Delgado Gonzáles Ana Alvarez Barcena
https://orcid.org/0000-0002-1071-212X https://orcid.org/0000-0003-3823-4737 https://orcid.org/0000-0003-3527-7272 https://orcid.org/0000-0002-4208-1748 https://orcid.org/0000-0002-1308-1159 